\begin{tabular}{|c|c|c|}
\hline PORT SAID ENGINEERING RESEARCH JOURNAL & Faculty of Engineering - Port Said University \\
\hline & Volume 18 & No. $2 \quad$ September2014
\end{tabular}

\title{
Solving the Upconing Pumping Problem and Hydrodynamic Dispersion in Coastal Unconfined Aquifers
}

\author{
Mohamed M. A. Somaida ${ }^{1}$ (Faculty of Engineering, Port Said University)
}

\begin{abstract}
:
In the present study, the salt-water up coning problem in coastal unconfined aquifers is investigated. The dimensional analysis is used to provide information about the optimum well depth and the optimum pumping rate for a well suggested to be partially penetrating a coastal unconfined aquifer example. The Bear and Todd's method of superimposing the effects of hydrodynamic dispersion on the up coning system, is used to predict the concentration profile with depth below the pumped example well at a workable dispersivity of the aquifer. The results shows that, the concentration of pumped water is still suitable for irrigation under certain conditions. Comparison of the estimated salinity profile for the example well, with the measured salinity profile in a neighboring well drilled in the same area, indicates an order of magnitude agreement. The results encourage the use of the present solution methodology of the up coning pumping system problem as it seems to be extremely useful in the cases where the dispersion measurements are unavailable in the studied aquifer.
\end{abstract}

Keywords : Well drawdown, Radius of Influence, Interface, Permissible Well Discharge, Dispersion Coefficient, Dispersivity, Transition Zone, Salt-Concentration of Groundwater, Coastal areas.

\section{Introduction}

Salt water up coning has been a problem in groundwater utilization for many coastal aquifers, such as the Pleistocene aquifer of the north-western coastal zone of Egypt/1,2)

1. Consequently, a number of papers have been published which describe means for investigating the characteristics of salt-water up coning and intrusion under various circumstances, /3to6/. In paper $/ 6 /$, the behavior of local up coning around a pumping well in unconfined aquifers is investigated and operational and well-design criteria are established for the case of radial flow to a well fully penetrating an unconfined aquifer. The present study, analyzes and studies an up coning pumping problem in an unconfined aquifer ,this is being based on two concepts; firstly, use of dimensional analysis to provide information about the optimum depth for a well partially penetrating the aquifer and its permissible well discharge. Secondly, predicting the variation of groundwater concentration with depth in the pumped well. Finally, application of the solutions reached on the coastal unconfined aquifer in Sidi Kreir Locality for the case of an upconing pumping problem.

\section{Upconing}

When fresh water is underlain by saline water, pumping a well in the fresh zone causes the interface to rise below the well, Fig(1). This up coning is in response to the pressure reduction on the interface due to the drawdown of the water table around the well. If the bottom of the well is close to the saline water or the well discharge is relatively high, the salt-water cone may reach into the well, causing the well discharge to be a mixture of fresh and saline water ground water. This process may take a few months or many years depending on various factors as aquifer properties and geometry of the up coning system .

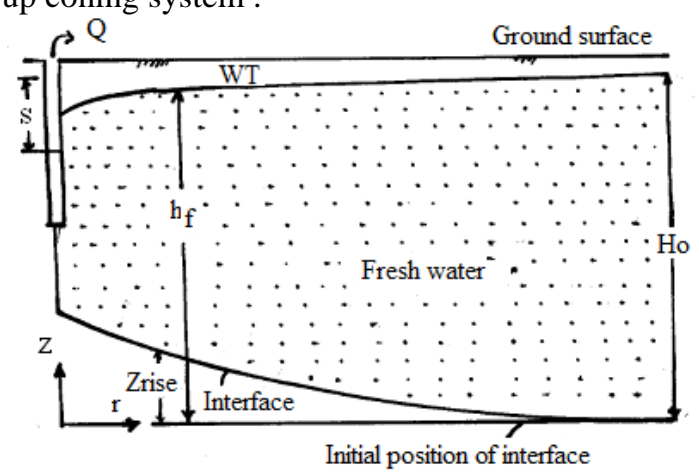

Figure 1: Simplified sketch for an unconfined aquifer with salt base and abrupt interface. 
In reality, the drawdown cone may reach a constant head recharge boundary or the aquifer may be naturally recharged from rainfall infiltration which will eventually bring the system to a steady-state condition or both may occur. According to, $/ 6 /$, in the case of small diameter well, Fig (2), numerical results of up coning show that, at a given pumping rate, the interface rises with time at almost the same rate for different well depths, although the magnitude is slightly larger for a deeper well. Both magnitude and time rate of interface rise are significantly affected by the pumping rate.

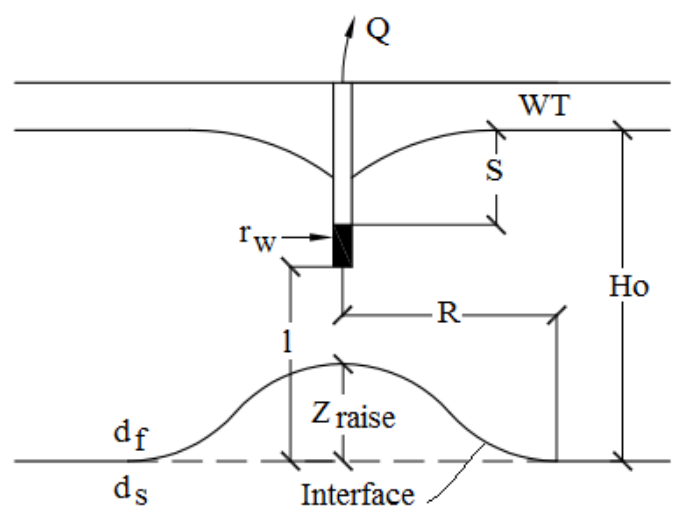

Figure 2:Small diameter pumped well partially penetrating and un confined aquifer with salt base.

\subsection{Dimensional Analysis for Up coning System}

Consider an unconfined coastal aquifer with abrupt interface between fresh and salt water. The flow domain is distinctly divided into ; two zones, one for fresh water and the other for salt water. Consider a small diameter well is partially penetrating the aquifer, Fig(1). The well screen is provided through out the zone of saturation of the well bore.

The pumping rate $\mathrm{Q}$, from the well is a function of the independent parameters characterizing the up coning system $\frac{K_{z}}{K_{h}}, K_{h}, d_{s}$, $d_{f}, \Delta \mathrm{d}, \mathrm{s}, H_{0}, \ell, \mathrm{R}$ and $r_{w}$, where $K_{z}=$ vertical hydraulic conductivity, $K_{h}=$ horizontal (radial) hydraulic conductivity, $d_{s}=$ density of salt water, $d_{f}=$ density of fresh water, $\Delta \mathrm{d}=$ density difference, $\mathrm{s}=$ drawdown, $H_{0}=$ thickness of aquifer, $\ell=$ height of well bottom above the initial position of interface, $\mathrm{R}=$ radius of influence and $r_{w}=$ well radius, If $K_{z}=K_{h}=\mathrm{K}$ (isotropic homogeneous aquifer), the functional relationship can be written as :
$\mathrm{f}\left(\mathrm{Q}, \mathrm{K}, d_{s}, d_{f}, \Delta \mathrm{d}, \mathrm{s}, \ell, H_{0}, \mathrm{R}, r_{w}\right)=0$ (1),

If the parameters $\mathrm{K}, d_{s}$ and $H_{0}$ are chosen to dimensionlize on in the Buckingham $\pi$ theorem, the following independent dimensionless parameters characterizing the system are obtained :

$\pi 1=\frac{Q}{K H 02}, \pi 2=\frac{\Delta d}{d s}, \pi 3=\frac{s}{H 0}, \pi 4=\frac{R}{H 0}, \pi 5=$ $\frac{l}{H 0}$ and $\pi 6=\frac{r w}{H 0}$

Hence, the functional relationship will be:

$$
\mathrm{F}\left(\frac{Q}{K H 02}, \frac{\Delta d}{d s}, \frac{s}{H 0}, \frac{R}{H 0}, \frac{l}{H 0}, \frac{r w}{H 0}\right)=0
$$

In small diameter wells: the parameter $\frac{r w}{H 0}$, can be neglected. Since, a functional relationship between $\frac{l}{H 0}$ and $\mathrm{Q}$ is to be established for a given value of $\mathrm{K}$, a new dimensionless parameter grouping is formed, so it includes all the characteristic parameters except $\frac{r w}{H 0}$, and $\frac{l}{H 0}$, then :

$$
\mathrm{F}\left(\frac{Q}{K H 02}, \frac{\Delta d}{d s}, \frac{s}{H 0}, \frac{R}{H 0}\right)==0
$$

A combination between $\pi 1, \pi 2, \pi 3$ and $\pi 4$ leads a new dimensional parameter $\pi$, which can be written in general as :

$$
\pi=(\pi 1)^{a}(\pi 2)^{b}(\pi 3)^{c} \ln (\pi 4)^{d}
$$

From the initially expected relationships between $\mathrm{Q}$ and each parameter, it is found that, $\mathrm{a}=1, \mathrm{~b}=$ $1, \mathrm{c}=-1$ and $\mathrm{d}=1$, hence equation(5) will take the form;

$$
\pi=\frac{Q}{K H 0^{2} s \frac{\Delta d}{d s}} \ln \frac{R}{H 0} \quad \text { (6) ahmed }
$$

From Ghyben-Herzberg relation :

$$
\mathrm{s}=\frac{\Delta d}{d f} Z_{r}
$$

where $z_{r}=$ interface rise measured from reference level. Substitute $s$ of equation(7) in equation(6), then :

$$
\pi=\frac{Q}{K H 0^{2}}\left(\frac{1}{(z r)}\right)\left(\frac{1}{\frac{\Delta d 2}{d s d f}}\right) \ln \frac{R}{H 0}
$$

\subsection{Permissible Pumping Rate}

The permissible pumping rate $Q_{p}$ is of interest for the up coning problem and is defined as the pumping rate at the critical $\operatorname{rise}\left(z_{r}\right) \mathrm{cr}$. The critical rise is, in term defined as the interface rise at the pumping well above which the rate of rise with respect to the pumping rate is accelerated, /6/. Bear and Dagan, /3/, show that, at value of $\frac{z r}{l}=0.2$ to 0.33 , the rate of rise is accelerated. In addition to, at a small pumping rate, the interface rises up to an equilibrium position and forms a flat-bell shaped interface, 
Fig (2). The interface moves further up if pumping rate is increased and will reach the well bottom when a maximum pumping rate is attained. It is for that, the interface rise ratio $\left(\frac{z r}{l}\right)$ increases linearly with the pumping rate at a value of about 0.35 , after which it increases at greater rate. However, a value of $\left(\frac{z r}{l}\right)$ of $0.350 \mathrm{r}$ $\left(z_{r}\right) \mathrm{cr}=0.35 \ell$ is convenient for the present study. Accordingly, the permissible pumping rate $Q_{p}$ incorporated in equation(8) gives :

$$
\pi=\frac{Q p}{K(H 0)^{2}}\left(\frac{1}{(\text { zrise }) c r}\right)\left(\frac{1}{\frac{\Delta d 2}{d s d f}}\right) \ln \frac{R}{H 0}
$$

All the parameters in equation(9) are known except $\pi, Q_{p}$ and $\mathrm{R}$. The well pumping rate $Q_{p}$ can be determined by an earlier formula given by, Muskat ,/7/,for a well partially penetrating a confined aquifer :

$Q_{p}=\frac{2 \pi K b s}{\ln \frac{R}{r w}} \alpha\left(1+7 \sqrt{\frac{r w}{2 \alpha b}} \cos \frac{\pi}{2} \alpha\right)$

Where $b=$ thickness of the confined aquifer and $\alpha=$ penetration fraction of the well. For a well partially penetrating a confined aquifer, in equation(10), b can be replaced by H0 (thickness of the unconfined aquifer) and $\alpha$ by $\left(1-\frac{l}{H 0}\right)$, then :

$$
\begin{aligned}
& Q_{p}=\frac{2 \pi K H 0 s}{\ln \frac{R}{r w}}\left(1-\frac{l}{H 0}\right)\left(1+7\left(\sqrt{\frac{r w}{2 H 0\left(1-\frac{l}{H 0}\right)}}\right)\right. \\
& \left.\cos \frac{\pi}{2}\left(1-\frac{l}{H_{0}}\right)\right)
\end{aligned}
$$

All the parameters in the right-hand side of equation(11) will be given in the aquifer example except the radius on influence $R$.

\subsection{Radius of Influence}

The distance from well to where the drawdown is negligible is called the radius of influence $(R)$. The equation for estimating it, can be written in the general form :

$$
\mathrm{R}=\mathrm{C} \sqrt{\frac{T t}{S}}
$$

Where $\mathrm{C}=$ multiplying coefficient, $\mathrm{T}=$ transmissivity of the aquifer, $\mathrm{t}=$ time since pumping started and $\mathrm{S}=$ specific yield of the unconfined aquifer. Values of $\mathrm{C}$ ranges from 1.5 to $4.3, / 4 /,$. On the other hand, different up coning systems in an unconfined aquifer are studied by, $/ 6 /$, at various values of $\frac{l}{H 0}$, with the coefficient $\mathrm{C}$ computed and plotted versus $\left(\frac{l}{H 0}\right), \operatorname{Fig}(3)$. This figure is helpful in estimating the multiplying coefficient $\mathrm{C}$ for up coning systems similar in pattern to those of Fig(3), provided that, stead y-state behavior is reached and the flow in the salt section is uniform and vertically upward.

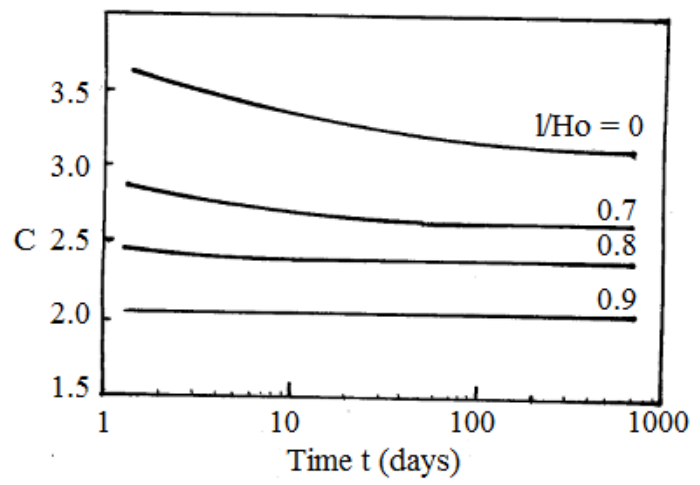

Figure 3: Radius of influence multiplying coefficient $\mathrm{C}$ for small diameter well in an unconfined aquifer, with $\left(\frac{K_{z}}{K_{h}}=1, H_{0}=30 \mathrm{~m}\right.$, $\frac{l}{H_{0}}=0: 0.9$ and $\left.\mathrm{S}=0.1\right)$, after $(6)$.

\section{Application Example}

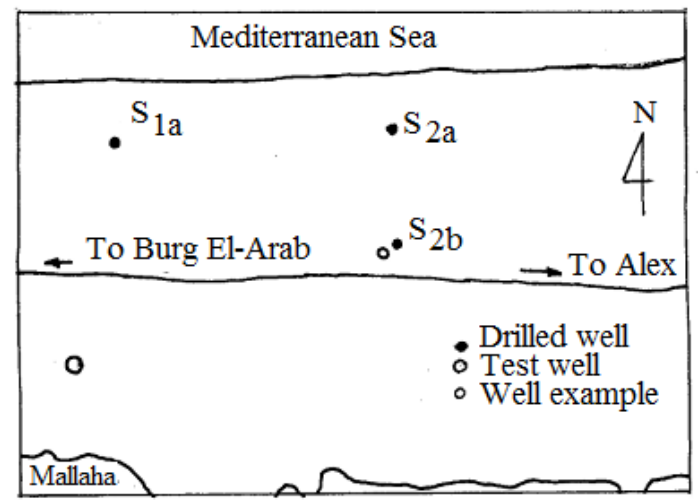

Figure 4: Index map of Sidi-Kreir locality.

The previous up coning analysis will be applied on a suggested small diameter well partially penetrating the coastal unconfined aquifer in Sidi Kreir locality, $32 \mathrm{~km}$ west of Alexandria, Fig(4). The proposed well is located close to the asphaltic road and is neighboring a drilled well $\left(S_{2 b}\right), \operatorname{Fig}(4)$.

\section{1 Geometric Aquifer Conditions}

The studied aquifer consists of carbonate rocks of Pleistocene age, (1), and is recharged from rainfall, where a part of it percolates downward to form a fresh-water lens floating on top of the underlying sea water according to Ghyben- 
Herzberg principle. For this aquifer the following data are given : Hydraulic conductivity of the aquifer considering partial penetration and anisotropy, $K_{f}=K_{s}=\mathrm{K}=16 \mathrm{~m} /$ day and specific yield $S=0.125,19 /$. Specific gravity of salt water $=1.025$ and that of fresh water $=1.0$, elevation of water table above sea level at the location of the well example $=0.88 \mathrm{~m}$, the thickness of the fresh-water aquifer $H_{0}=0.88 \times 41=36 \mathrm{~m}$. Depth of penetration of the well below water table $=3.6 \mathrm{~m}$, The depth of bottom of the well from the initial interface before pumping $\ell=$ $32.4 \mathrm{~m}$ and the radius of the well example $r_{w}=$ $0.15 \mathrm{~m}$.

In a test well in the study area, Fig (4), it is pumped for 5 hours period with a rough steady state condition /1,9/. According to/10/, the condition of steady state is generally satisfied within several hours in the case of water table aquifers because the groundwater flow is draining from the interstices. However, In Sidi Kreir locality, for wells close to the asphaltic road where the fresh-water aquifer attains its maximum thickness, (1), the time of pumping till reaching a complete steady-state condition, may be accepted to be at least one day.

\subsection{Calculations and Results}

For the test well in the study area, $\mathrm{K}=16$ $\mathrm{m} /$ day, $H_{0}=36 \mathrm{~m}, \mathrm{~S}=0.125$ and $\frac{l}{H 0}=0.9, \mathrm{R}=$ $125 \mathrm{~m}$, (9). Under these conditions, application of equation(12) gives $\mathrm{C}=1.84$, which is within the permissible range. On the other hand, use of Fig(3) at one day pumping and $\frac{l}{H 0}$ ranges from 0 to 0.9 , gives the values of $\mathrm{C}$ as shown in Table(1) ,6). The values of $\mathrm{C}$ for the studied aquifer are interpreted by correlation with the values in Table(1) at the same values of $\frac{l}{H_{0}}$ because both aquifers are geometrically similar.

Table 1: Multiplying coefficient $\mathrm{C}$ evaluated for the studied aquifer

\begin{tabular}{|c|c|c|c|c|c|c|c|c|c|c|}
\hline$\frac{l}{H 0}$ & 0.0 & 0.1 & 0.2 & 0.3 & 0.4 & 0.5 & 0.6 & 0.7 & 0.8 & 0.9 \\
\hline $\mathrm{C}$ ( Fig.3) & 3.65 & 3.55 & 3.43 & 3.32 & 3.24 & 3.15 & 3.06 & 2.9 & 2.46 & 2.04 \\
\hline C(aquifer ex.) & 3.28 & 3.15 & 3.1 & 3.0 & 2.91 & 2.83 & 2.74 & 2.6 & 2.2 & 1.84 \\
\hline
\end{tabular}

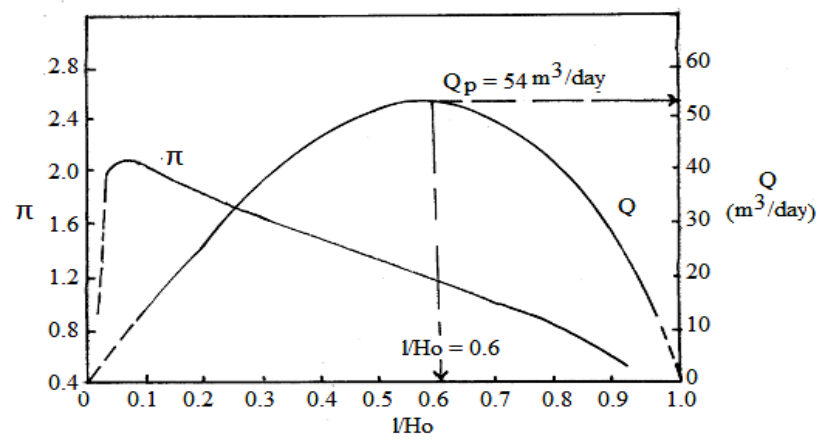

Figure 5: Functional parameter relationships for the well example $\left(\mathrm{r}_{\mathrm{w}}=15 \mathrm{~cm}, \frac{K_{z}}{K_{h}}=1, H_{0}=30 \mathrm{~m}\right)$ for the studied upconing system.

All the data necessary to calculate $\mathrm{R}, Q_{p}$ and the functional dimensional parameter $\pi$ expressed by equation(11), are available. The results of these parameters are shown in Table (2). The plots of $\left(\frac{l}{H 0}\right)$ versus $\pi$ as well as $Q_{p}$ for the studied up coning system are shown in Fig(5). The curve suggests that the optimum value of( $\left.\frac{l}{H 0}\right)$ is 0.6 and the corresponding permissible discharge is $54 \mathrm{~m}^{3} /$ day

\subsection{Steady-State Behavior}


A steady-state up coning system with different pumping rates, is studied by, /6/.As stated before, at a small pumping rate the interface rises up to an equilibrium position and forms a bell-shaped interface. This interface moves further up if the pumping rate is increased and will reach the well bottom when a maximum pumping rate is attained. To illustrate this for the studied well example, the normalized interface rise ratio at the well $\left(\frac{\text { zrise }}{l}\right)$, is plotted versus pumping rate, Fig $(6)$ at $\left(\frac{l}{H 0}\right.$ ) $=0.6$, based on the results illustrated in Table(2), A very interesting aspect of up coning behavior is revealed, The interface rise ratio $\left(\frac{z \text { rise }}{l}\right)$, increases at a lower pumping rate up to a value of 0.35 , where the discharge has its optimum value (54 m3/day). After which, it increases at greater rate. When $\left(\frac{z r i s e}{l}\right)$ moves up to about 0.7 , the rate at which it increases with respect to the pumping rate is so high that it almost increases simultaneously. These conclusions are identical with those given in, $/ 6 /$, where it is stated that the zone of instantaneous rise is well defined at $\frac{\text { zrise }}{l}$ above 0.5 for several studied cases.

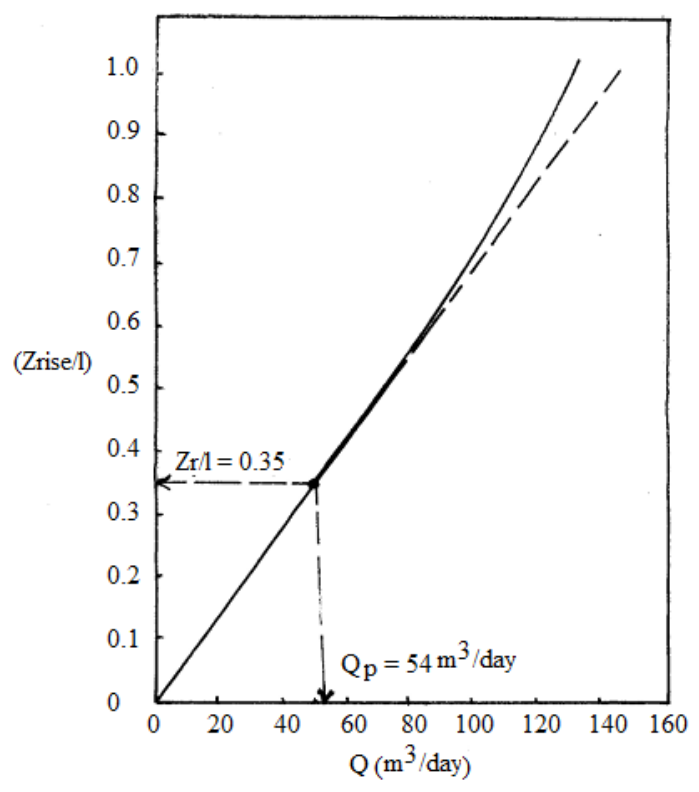

figure 6: Rise of interface for the well example as a function of pumping rate for the studied upconing system $\left(\frac{l}{H_{0}}=0.6\right)$

Table 2. Various geometric aquifer conditions for the studied up coning System, $\left(\frac{z r i s e}{l}\right) \mathrm{cr}=0.35$

\begin{tabular}{|c|c|c|c|c|c|c|c|c|c|c|}
\hline$\frac{l}{H 0}$ & $\ell(\mathrm{m})$ & $\begin{array}{c}\mathrm{zr}(\mathrm{cr}) \\
(\mathrm{m})\end{array}$ & $S_{c r}(\mathrm{~m})$ & $\mathrm{t}($ day $)$ & $\mathrm{C}$ & $\mathrm{R}(\mathrm{m})$ & $\ln \left(\frac{R}{H 0}\right)$ & $\ln \left(\frac{R}{r w}\right)$ & $\begin{array}{c}Q_{p} \\
\left(\mathrm{~m}^{3} / \mathrm{day}\right)\end{array}$ & $\pi$ \\
\hline 0.01 & 0.36 & 0.126 & 0.00315 & 1 & 3.32 & 225.4 & 1.83 & 7.32 & 1.55 & 1.78 \\
\hline 0.05 & 1.8 & 0.63 & 0.015575 & 1 & 3.23 & 219.3 & 1.81 & 7.28 & 7.63 & 1.73 \\
\hline 0.1 & 3.6 & 1.26 & 0.0315 & 1 & 3.19 & 216.6 & 1.79 & 7.27 & 16.5 & 1.86 \\
\hline 0.2 & 7.2 & 2.52 & 0.063 & 1 & 3.1 & 210.5 & 1.77 & 7.25 & 27.9 & 1.55 \\
\hline 0.3 & 10.8 & 3.78 & 0.0945 & 1 & 3 & 203.7 & 1.73 & 7.21 & 38.9 & 1.41 \\
\hline 0.4 & 14.4 & 5.04 & 0.14 & 1 & 2.91 & 167.6 & 1.7 & 7.18 & 46.7 & 1.24 \\
\hline 0.5 & 18.0 & 6.3 & 0.158 & 1 & 2.83 & 192.2 & 1.68 & 7.12 & 52.8 & 1.11 \\
\hline 0.6 & 21.6 & 7.56 & 0.189 & 1 & 2.74 & 186.1 & 1.64 & 7.11 & 54.1 & 0.93 \\
\hline 0.7 & 25.2 & 8.72 & 0.221 & 1 & 2.6 & 176.5 & 1.59 & 7.07 & 51.4 & 0.73 \\
\hline 0.8 & 28.8 & 10.08 & 0.252 & 1 & 2.2 & 149.4 & 1.42 & 6.9 & 44.53 & 0.5 \\
\hline 0.9 & 32.4 & 11.34 & 0.289 & 1 & 1.84 & 124.9 & 1.24 & 6.72 & 30.5 & 0.27 \\
\hline
\end{tabular}


Table 3. Various geometric aquifer conditions for the studied up coning System, at $\left(\frac{l}{H 0}\right)=0.6$

\begin{tabular}{|c|c|c|c|c|c|c|c|c|c|c|}
\hline$\frac{l}{H 0}$ & $\left(\frac{z r}{l}\right)$ & $\mathrm{zr}(\mathrm{m})$ & $\mathrm{s}(\mathrm{m})$ & $\mathrm{t}($ day $)$ & $\mathrm{C}$ & $\mathrm{R}(\mathrm{m})$ & $\ln \left(\frac{R}{H 0}\right)$ & $\ln \left(\frac{R}{r w}\right)$ & $\begin{array}{c}Q_{p} \\
\left(\mathrm{~m}^{3} / \mathrm{day}\right)\end{array}$ & $\pi$ \\
\hline 0.6 & 0.05 & 1.08 & 0.027 & 0.9 & 2.75 & 177.1 & 1.6 & 7.07 & 7.8 & 0.912 \\
\hline 0.6 & 0.1 & 2.16 & 0.054 & 1 & 2.74 & 186 & 1.64 & 7.12 & 12.9 & 0.93 \\
\hline 0.6 & 0.2 & 4.32 & 0.108 & 1.1 & 2.73 & 194.4 & 1.69 & 7.11 & 30.7 & 0.95 \\
\hline 0.6 & 0.3 & 6.48 & 0.162 & 1.2 & 2.72 & 202.2 & 1.73 & 7.21 & 45.8 & 0.97 \\
\hline 0.6 & 0.4 & 8.64 & 0.216 & 1.3 & 2.70 & 209 & 1.76 & 7.24 & 60.8 & 0.98 \\
\hline 0.6 & 0.5 & 10.8 & 0.27 & 1.4 & 2.69 & 215.7 & 1.79 & 7.27 & 75.73 & 1.0 \\
\hline 0.6 & 0.6 & 12.96 & 0.324 & 1.5 & 2.67 & 222 & 1.82 & 7.30 & 90.5 & 1.0 \\
\hline 0.6 & 0.7 & 15.12 & 0.378 & 1.6 & 2.65 & 227.5 & 1.84 & 7.32 & 105.3 & 1.01 \\
\hline 0.6 & 0.8 & 17.28 & 0.432 & 1.7 & 2.64 & 233.7 & 1.87 & 7.35 & 119.8 & 1.026 \\
\hline 0.6 & 0.9 & 19.44 & 0.486 & 1.8 & 2.62 & 238.6 & 1.89 & 7.37 & 134.45 & 1.03 \\
\hline
\end{tabular}

\section{Effects of Hydrodynamic Dispersion Below The Well}

In fact, in an unconfined aquifer with saline base, a transition zone rather than an abrupt interface exists between the fresh and salt water. However, in many cases, the assumption of an abrupt interface is a good approximation of the transient average position of the transition zone, (3), provided that, the concentration distribution in the transition zone has an error function form (8).

The governing equation for longitudinal hydrodynamic dispersion in a homogeneous porous medium is :

$$
D_{L}\left(\frac{\partial 2 c}{\partial z 2}\right)=\left(\frac{\partial c}{\partial t}\right)+\mathrm{v}\left(\frac{\partial c}{\partial z}\right)
$$

In which, $D_{L}=$ longitudinal dispersion coefficient, $\mathrm{c}=$ concentration, $\mathrm{v}=$ average velocity of the fluid, $\mathrm{z}=$ coordinate parallel to the flow and $\mathrm{t}=$ time. The analytical solution of equation(13)is,/11,12/ :

$$
\begin{gathered}
\frac{c}{c_{0}}=\frac{1}{2} \quad\left(\operatorname{erfc}\left(\frac{z-v t}{2 \sqrt{D L t}}\right)+e^{\frac{v z}{D L}} \quad \operatorname{erfc}\right. \\
\left.\left(\frac{z+v t}{2 \sqrt{D L} t}\right)\right)
\end{gathered}
$$

Where $\mathrm{c}=$ concentration, $c_{0}=$ reference concentration and erfc $=$ complementary error function. According to, /11,12,13/, the second term of the right-hand side of equation(14) is generally small. Thus a good approximation to the solution may be written as :

$$
\frac{c}{c_{o}}=\frac{1}{2} \operatorname{erfc}\left(\frac{z-v t}{2 \sqrt{D L} t}\right)
$$

The analytical approach in equation(15), has been applied by Schmorak and Mercado, /5/, for up coning. The problem is treated as a onedimensional upward, solute transport process with abrupt interface representing the center of the transition zone( $50 \%$ fresh-salt water mixture). Therefore, the salinity profile $\mathrm{c}(\mathrm{z})$, as a function of the vertical distance from the initial interface $(z)$, the travelled distance of the interface center(z rise) and dispersivity $a_{1}=\left(\frac{D L}{v L}\right)$ or $D_{L}=a_{1} v_{L}$, is strongly approximated by :

$$
\mathrm{c}(\mathrm{z})=\frac{1}{2} \operatorname{erfc}\left(\frac{z-\text { zrise }}{2 \sqrt{a 1} \text { zrise }}\right)
$$

Where $\mathrm{c}(\mathrm{z})=\left(\frac{C-C f}{C s-C f}\right)=-$ normalized concentration, $\mathrm{C}=$ salt concentration of water, Cs $=$ salt concentration of salt water and $C_{f}=$ salt concentration of fresh water and $a_{1}=$ dispersivity of the aquifer and $v_{L}=$ longitudinal velocity of flow in the porous medium. It is also assumed that, the flow in the salt section is uniform and vertically upward in the region of up coning.

In equation(16), dispersivity $a_{1}$ is theoretically a constant with dimensions of length. It may be above $20 \mathrm{~m}, / 14 /$. or smaller as $5 \mathrm{~m}, / 5 / . \mathrm{In}$ equation(16), the length of transition zone $(2 \sigma)$, as a function of the interface travelled distance (zrise) and the dispersivity $a_{1}$, is given by, $/ 5 /$ :

$2 \sigma=\sqrt{2} a_{1}$ zrise

In which $\sigma$ is defined as, (5) :

$$
\sigma=\frac{1}{2}\left(z_{c=0.159}-z_{c=0.841}\right)
$$

From equation((17), it can be concluded that :

$$
a_{1}=\left(\frac{\sigma 2}{2 \text { zrise }}\right)
$$

Evaluation of $a_{1}$ is helpful in the solution of equation(16) as will be shown later.

To estimate the concentration of the pumped water, Schmorak and Mercado, /5/,relate the normalized salt concentration of pumped water 
$\mathrm{cp}$ to the average concentration of the transition zone above the interface at the pumping well c' as :

$$
\mathrm{cp}=\beta c^{\prime}
$$

In which $\beta=$ correlation coefficient which may be determined from the field measurements. Reported values of $x$ ranges from 0.05 and 0.08 , 15/. The real salt concentration of pumped water $\left(C_{p}\right)$, is computed as :

$$
C_{p}=\mathrm{cp} C s+(1-\beta) C_{f}
$$

\subsection{Hypothetical Concentration Profile Below The Pumped Well Example}

To illustrate the hypothetical concentration profile computed for the well example, Fig(4), the following data are given : $C_{f}$ (concentration of fresh water $)=2$ mmhos $(1280 \mathrm{ppm})$, $C_{s}$ (concentration of saline water) $=50 \mathrm{mmhos}$ (32000 ppm), optimum $\frac{l}{H_{0}}=0.6$, from Fig(5), $\ell$ $=0.6 \times 36=21.6 \mathrm{~m}$ and zrise $=0.351=0.35 \times 21.6$ $=7.56 \mathrm{~m}$. The intensive electrical conductivity measurements in Sidi Kreir Locality conducted in the drilled wells $S_{1 a}, S_{2 a}$ and $S_{2 b}$, Fig(4), given in plates 3,6 and $7, / 15 /$, show that, the thickness of fresh-water lens in these wells occurs according to Ghyben-Herzberg principle. Investigation of the salinity profiles recorded in these wells, shows that, the average salinity gradient in well $S_{1 a}$ is $1.82 \mathrm{mmhos} / \mathrm{m}$, while in $S_{2 a}$ is $1.6 \mathrm{mmhos} / \mathrm{m}$ and $3.1 \mathrm{mmhos} / \mathrm{m}$ depth in well $S_{2 b}$. On the average, the salinity gradient is $2.17 \mathrm{mmhos} / \mathrm{m}$ depth. Referring to equation(18), the length of transition zone $(2 \sigma)$ will be $=$ $\left(\frac{0.841 \times 50-0.159 \times 50}{2.17}\right)=15.7 \mathrm{~m}$ where the 50 mmhos is taken as the reference concentration or $(\sigma)=7.85 \mathrm{~m}$. Then, by the use of equation(19), $a_{1}=\left(\frac{2.85^{2}}{2 \times 7.56}\right)=4.075 \mathrm{~m}$ or simply taken $4 \mathrm{~m}$. This value is in order of magnitude agreement and accepted for the dispersivity coefficient of the studied aquifer.

According to, $/ 15,16 /$, it is found that, below the fresh-water layer at the site of well example, the salinity increases with depth, where the sea water ( $\geq 50$ mmhos) at $28 \mathrm{~m}$ from the water table (38 $\mathrm{m}$ from the ground surface). However, for calculation purposes, the 0-level of the $\mathrm{z}$ coordinate is taken at $38 \mathrm{~m}$ depth which is the level of the suggested initial fresh-salt water interface before pumping in the example well.

According to the available data, the hypothetical concentrations in the example well are estimated as function of $\mathrm{z}(10-38 \mathrm{~m})$, using equation(16). The results are given in Table (4). Its corresponding plot is illustrated in Fig(7).
From this figure, the average concentration of the transition zone c' (at $\mathrm{c}(\mathrm{z})=0.5)$, is estimated to be 0.148 . Also, the normalized salt concentration of pumped water $\mathrm{cp}$ is computed by equation(20) at $\beta=0.08$ as $\mathrm{cp}=0.08 \times 0.148=0.1184$. Finally, the real concentration of pumped water $C_{p}$ is computed by equation(21) and found = $0.01184 \times 32000+(1-0.01184) 1300=$ $1663.485 \mathrm{ppm}$ (2.6 mmhos). According to $/ 17 /$,the upper permissible limit of electrical conductivity for safe use of water in irrigation is (6 - 8) mmhos for semi-tolerant and tolerant crops respectively, for soils having excellent internal and surface drainage. If these limits are considered, then for the studied aquifer, the pumped water from the well example after an interface rise of $7.56 \mathrm{~m}$, may still be suitable for irrigation.

\subsection{Comparison Between Hypothetical and Measured Concentration Profiles}

According to, $/ 15,16 /$, the well $S_{2 b}$, Fig(4), is drilled down to a depth of $38 \mathrm{~m}$, while the depth of water table is $10 \mathrm{~m}$. The well is completely penetrating the aquifer and its discharge is estimated to be $63 \mathrm{~m} 3 /$ day, which is of nearer magnitude to the value of $54 \mathrm{~m} 3 /$ day estimated for the neigh-boring well example, i.e.,both wells are subjected nearly to the same prevailing conditions. For comparison purposes, the detailed electrical conductivity measurements and its increasing rate with depth are also given in Table (4) and illustrated in the graph of Fig(7), which show a relatively sigmoid break through curve characteristic of equation (16).

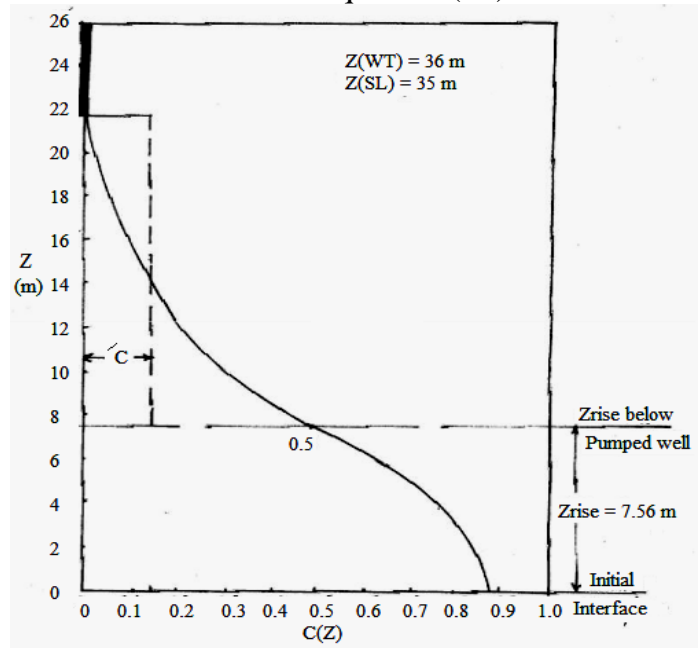

Figure 7: Hypothetical concentration profile below the pumped well example.

In the coastal aquifers, fresh water is physically defined as that water having density $1.0 \mathrm{gm} / \mathrm{cm} 3$ 
which is floating over salt water of density 1.025 $\mathrm{gm} / \mathrm{cm} 3$. In terms of total salinity expressed in electrical conductivity/cm at $25^{\circ} \mathrm{C}$, it is classified as follows, /18/ :

Fresh water

2 mmhos
Passably fresh water

Brackish water

Salt water

Extremely salt water
2-4 mmhos

4-9 mmhos

9-50 mmhos

$>50$ mmhos

Table. 4 Estimated and measured water concentrations in the well example and drilled Well S2b, Sidi Kreir Locality

\begin{tabular}{|c|c|c|c|c|}
\hline Depth (m) & $\mathrm{z}(\mathrm{m})$ & $\mathrm{C}(\mathrm{z})$ & $\begin{array}{c}\text { Hypoth.C (mmhos) } \\
\text { Ex. well }\end{array}$ & $\begin{array}{c}\text { Measured C (mmhos) } \\
\text { Well S2b }\end{array}$ \\
\hline 10 & 28 & 0.003 & 2.13 & 2.1 \\
\hline 11 & 27 & 0.004 & 2.2 & 2.3 \\
\hline 12 & 26 & 0.006 & 2.3 & 2.5 \\
\hline 13 & 25 & 0.009 & 2.43 & 2.6 \\
\hline 14 & 24 & 0.013 & 2.62 & 2.7 \\
\hline 15 & 23 & 0.018 & 2.87 & 2.7 \\
\hline 16 & 22 & 0.025 & 3.21 & 2.7 \\
\hline 17 & 21 & 0.034 & 3.64 & 2.7 \\
\hline 18 & 20 & 0.046 & 4.2 & 2.7 \\
\hline 19 & 19 & 0.06 & 4.9 & 2.7 \\
\hline 20 & 18 & 0.078 & 5.77 & 2.7 \\
\hline 21 & 17 & 0.1 & 6.81 & 2.7 \\
\hline 22 & 16 & 0.126 & 8.06 & 2.7 \\
\hline 23 & 15 & 0.157 & 9.51 & 3.6 \\
\hline 24 & 14 & 0.191 & 11.18 & 4.4 \\
\hline 25 & 13 & 0.23 & 13.06 & 18.5 \\
\hline 26 & 12 & 0.274 & 15.13 & 32.5 \\
\hline 27 & 11 & 0.32 & 17.38 & 36.4 \\
\hline 28 & 10 & 0.37 & 19.78 & 40.3 \\
\hline 29 & 9 & 0.423 & 22.28 & 40.9 \\
\hline 30 & 8 & 0.476 & 24.86 & 41.6 \\
\hline 31 & 7 & 0.7 & 35.6 & 41.9 \\
\hline 32 & 6 & 0.74 & 37.52 & 42.1 \\
\hline 33 & 5 & 0.75 & 38 & 42.9 \\
\hline 34 & 4 & 0.76 & 38.48 & 43.7 \\
\hline 35 & 3 & 0.77 & 38.96 & 44.8 \\
\hline 36 & 2 & 0.84 & 42.32 & 45.9 \\
\hline 37 & 1 & $\begin{array}{l}0.88 \\
\end{array}$ & 44.24 & 49.8 \\
\hline 38 & 0 & 0.885 & 44.48 & 50 \\
\hline
\end{tabular}

On comparison basis and following the previous groundwater salinity classification, then investigation of the estimated and measured salinity profiles of well example and drilled well $S_{2 b}$, Table (4) and Fig(8) indicates that :

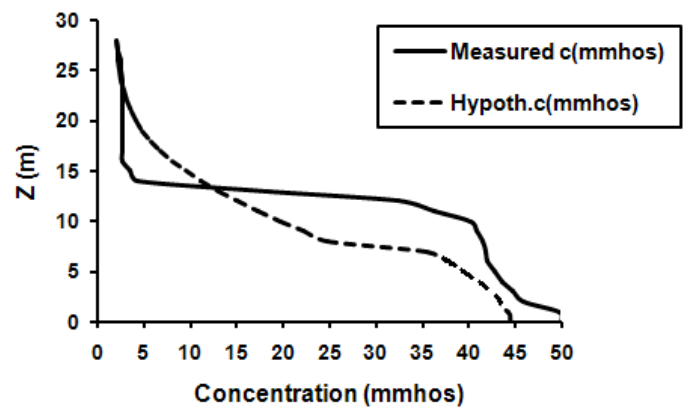

Figure 8: Variations of water concentrations with depth for well example and drilled well $S_{2 b}$, Sidi-Kreir locality.

(1)There is a marked decrease in salinity values in well $S_{2 b}$ below those estimated in the example well. According to , $/ 16 /$, this is caused by the decrease of $\mathrm{Mg}$ and $\mathrm{SO} 4$ contents in groundwater with depth (10-23.5 m).

(2) In depth interval from (23.5 to $38 \mathrm{~m}$ ), the salinity values measured in well $S_{2 b}$ are larger than those estimated for the example well, because at the well site, there is a continuous increase of concentration of $\mathrm{Na}, \mathrm{Cl}, \mathrm{Mg}$ and SO4 with depth, /16/. 
(3) In both wells, the rate of salinity change increases with depth, where the sea water is found at $38 \mathrm{~m}$ depth

(4) According to, $/ 18 /$, four water zones can be distinguished, Table(5), in accordance with electric conductivity behavior of groundwater in both wells which are summarized as follows :

(A) A zone of passably fresh water class (2-4 mmhos), of depth 10-17.2 $\mathrm{m}$ in example well, and from 10 to $23.5 \mathrm{~m}$ depth in well $S_{2 b}$. The corresponding changes in salinity ar 0.28 ad 0.15 $\mathrm{mmhos} / \mathrm{m}$ depth respectively

(B) A zone of brackish water (4-9 mmhos); from 17.2 to 22.65 depth in well example, while being from 23.5 to $24.3 \mathrm{~m}$ depth in well $S_{2 b}$. However, this zone is not diagnostic in this well

(C) A zone of brackish to saline water (9-50 mmhos), starting from 22.65 to $38 \mathrm{~m}$ depth in well example and from 24.3 to $38 \mathrm{~m}$ depth in well $S_{2 b}$. The corresponding changes in salinity are; 2.67 and $3 \mathrm{mmhos} / \mathrm{m}$ depth. This zone is in coincidence in both wells

(D) The fourth zone which is the actual sea water $>50 \mathrm{mmhos}$, where the actual sea water has been encountered at approximate depth of $28 \mathrm{~m}$ from water table and the salt water is extremely sinking downward

(5) On comparison basis, both concentration profiles have the same trend and the estimated and measured salinity values in both wells, have the same order agreement. This encourages the use of the present analysis for similar cases in coastal unconfined aquifers since, it is expected to be useful where the dispersion measurements are unavailable

Table 5. Classification of groundwater according to salinity profiles In Sidi Kreir Locality

\begin{tabular}{|l|c|c|c|c|c|}
\hline \multicolumn{1}{|c|}{ Water type } & $\begin{array}{c}\text { Salinity Range } \\
(\mathrm{mmhos})\end{array}$ & $\begin{array}{c}\text { Depth interval }(\mathrm{m}), \\
\text { Example well }\end{array}$ & $\begin{array}{c}\text { Salinity change } \\
(\mathrm{mmhos} / \mathrm{m})\end{array}$ & $\begin{array}{c}\text { Depth interval }(\mathrm{m}), \\
\text { well } S_{2 b}\end{array}$ & $\begin{array}{c}\text { Salinity change } \\
(\mathrm{mmhos} / \mathrm{m})\end{array}$ \\
\hline Passably fresh & $2-4$ & $10-17.2$ & 0.28 & $10.0-23.5$ & 0.15 \\
\hline Brackish water & $4-9$ & $17.22-22.65$ & 0.92 & $23.5-24.3$ & 6.25 \\
\hline Salt water & $9-50$ & $22.65-38$ & 2.67 & $24.3-38$ & 3.0 \\
\hline Extremely salt water & $>50$ & $>38$ & $>2.67$ & $>38$ & $>3$ \\
\hline
\end{tabular}

\section{Conclusions}

In the present study, the salt-water up coning pumping problem, is solved for the coastal unconfined aquifer in Sidi Kreir Locality. Dimensional analysis is applied on a suggested well example to determine; the optimum penetration well ratio and the permissible discharge for safe yield of the aquifer. The Bear and Todd,s method for superimposing the effects of hydrodynamic dispersion in the up coning pumping system is used to predict the hypothetical variations in concentration of pumped water with depth below the pumping well example. The estimated concentration profile, shows that, after an interface rise of $7.56 \mathrm{~m}$ due to pumping, the salinity of pumped water may be still suitable for use in irrigation under certain conditions.

Comparison of salinity profile estimated below the well example with that measured actually in well $S_{2 b}$, indicates an order of magnitude agreement and a relatively sigmoid break through trend curves characteristic of equation (16). However, the present solution methodology of the up-coning pumping system in the coastal unconfined aquifer of Sidi Kreir Locality, is expected to be extremely useful for similar cases where the dispersion measurements are unavailable

\section{Nomenclature}

$\mathrm{Q}=$ well pumping rate
$K_{h}=$ horizontal hydraulic conductivity of aquifer

$K_{z}=$ vertical hydraulic conductivity of aquifer

$\mathrm{K}=$ hydraulic conductivity

$d_{f}=$ density of fresh water

$d_{s}=$ density of salt water

$\Delta \mathrm{d}=$ density difference

$\mathrm{s}=$ drawdown

$H_{0}=$ aquifer thickness

$\mathrm{L}=$ height of well bottom above initial interface

$\mathrm{R}$ = radius of influencer

$r_{w}=$ well radius

(z)rise $=$ interface rise measured from reference level

$Q_{p}=$ permissible pumping rate for safe yield

$\mathrm{T}=$ transmissivity of the aquifer

$\mathrm{t}=$ time elapsed since start of pumping

$\mathrm{S}=$ specific yield of aquifer

$\mathrm{c}(\mathrm{z})=$ normalized salt concentration of water

$\mathrm{z}=$ vertical coordinate ( positive upward)

$D_{L}=$ longitudinal dispersion coefficient

$v_{L}=$ upward velocity of rise of interface

$\mathrm{c}=$ concentration

$c_{0}=$ reference concentration

erfc $=$ complementary error function

$\mathrm{C}=$ salt concentration of water

$C_{f}=$ salt concentration of fresh water

$C_{s}=$ salt concentration of salt water

$a_{1}=$ dispersivity 
$2 \sigma=$ length of transition zone

$\mathrm{c}^{\prime}=$ average concentration of transition zone

$\mathrm{cp}=$ normalized salt concentration of pumped water

$\beta=$ normalized salt concentration coefficient

$C_{p}=$ Salt concentration of pumped water

\section{References}

/l/ Somaida, M.M., 1978 : A study of the fresh-water aquifer in Sidi Kreir area, west of Alexandria. Ph.D., Thesis, Faculty of Eng., Cairo University

2/ Hilmy, E., Elshazly, M.M., Tamer, M.A., and Korany, E., 1977 : Contribution to the hydrogeology of the -water bearing formations in the area between Burg Elk-Arab and El-Dada, north western coasta zone, Egypt. Desert Inst. Bull., ARE, 27, No. 2, 53-74

13/ Dagan, G., and Bear, G., 1968 : Solving the problem of local interface up coning in a coastal aquifer by the method of small perturbations. Journal of Hydraulic Research, Vol. 6. No. 1, 15-44/

14/ Rubin, H., and Pinder, G.F., 1977 : Approximate analysis of Up coning. Advances in Water Resources, Vo. 1, No. 2, 97-101

15/ Schmorak, S., and Mercado, A., 1969 : Upconing of fresh water-Sea water interface below pumping wells field study. Water resources Research, Vol. 5, No. 6, 1290-1311

/6/ Wirojanagud, P., and Charbeneau, R., 1985 : Saltwater upconing in unconfined aquifers. Journal of Hydraulic Eng., ASCE, Vol. 111, No. 3, 417-433

17/ Muskat, M., 1949 : Physical principles of oil production. McGraw-Hill Inc., New York, 205-270

18/ Bear, J., 1979 : Hydraulics of groundwater. First Edition, Mc-Graw Hill Inc, New York

19/ Somaida, M.M., 1986 : A study of the problem of partial penetration of the pumped wells and anisotropy in unconfined aquifers. Scientific Bull. , Ain Shams University, Faculty of Eng., No. 18, 1-23

110/ Wisler, C.O. and Brater, E.F., 1959: Hydrology. Jhon- Wiley Inc., 147-166

111/ Marino, M.A., 1973 : Londitudinal dispersion in saturated porous media. Journal of Hydraulic Eng., ASCE, Vol. 100, No. Hy 1,

1121/ Gradshteyn, I.S., and Ryzhik, 1965 : Tables of integrals series and products. Academic Press, New York 113/Bear, J., and Todd, D.J., 1960 : The transition between fresh and salt water in coastal aquifers. Water Resources Center Contrib. 29, University of California, Berkley, Calif.

/14/Bouwer, H., 1978 : Hydrology. Mc-Graw Hill Inc, $401 \mathrm{pp}$

/15/Abdel-Mogeeth, S.M., and Elshazly, M.M., 1980 : Characteristics of fresh-water lens in Sidi Kreir Locality, north-western coasta zone, Egypt. Desert Institute Bull., ARE, 30, No. 2, 1-15

/16/ Abel-Mogeeth, S.M., and Elshazly, MN.M., 1980 : Geochemistry of groundwater from Sidi Kreir area, north-western coastal zone, Egypt. Desert Institute Bull. , 30, No. 2, 149-168
/17/ Singh, S.D., and Murty, V.N., 1984 : Storage of fresh water in saline aquifers. Journal of Irrigation and Drainage division, ASCE, Vol.106, No. IR2, 93-104

118/ Hem, J.D., 1970 : Study and interpretation of the chemical characteristics of natural waters. U S Geol. Survey Water-Supply Paper, 1473, 363pp 